\title{
Landmark and PNS Guided Forearm Blocks
}

\author{
Surajit Giri ${ }^{1}$ \\ ${ }^{1}$ Department of Anaesthesiology, Pragati Hospital \& Research Centre, Sivasagar, Assam.
}

\section{Introduction}

Elbow block is used to provide anaesthesia and analgesia for hand and forearm surgery [1]. Primarily it is used to supplement or augment a proximal brachial plexus block if it is partial or patchy. Therefore elbow block is termed as rescue block by many Anaesthesiologists. In recent years, Ultrasonography(USG) guided distal blocks are studied with proximal brachial plexus block to accelerates anaesthesia onset time and block consistency for forearm surgeries [2]. Good anatomical knowledge of forearm nerves (Fig. A) is utmost mandatory to use elbow block as a primary anaesthetic technique for forearm and hand surgeries $[3,4]$.

\section{Indications}

1. Supplement and augment proximal brachial plexus block.

2. Forearm and hand surgeries.

\section{Instruments}

A marker, a measuring scale, peripheral nerve stimulator (PNS) machine,22G $50 \mathrm{~mm}$ insulated needle, ECG lead, 2\% lignocaine adrenaline, $0.5 \%$ bupivacaine, $2 \mathrm{ml}$ syringe for subcutaneous infiltration, one $5 \mathrm{ml}$ syringe loaded with $0.5 \%$ bupivacaine for PNS guided median, radial \& ulnar block, another $10 \mathrm{ml}$ syringe loaded with $0.25 \%$ bupivacaine for medial, lateral \& posterior cutaneous nerve block of forearm. Local anaesthetic (LA) are calculated according to the weight of the patient $(2 \mathrm{mg} / \mathrm{Kg}$ bupivacaine $\& 7 \mathrm{mg} / \mathrm{kg}$ lignocaine with adrenaline $)$.

\section{Following nerves can be blocked at elbow level}

\section{Median.}

2. Radial.

3. Ulnar.

4. Medial cutaneous nerve of forearm.

5. Lateral cutaneous nerve of forearm.

6. Posterior cutaneous nerve of forearm.

\section{Technique}

The side of upper limb to be blocked is confirmed. An appropriate informed consent (Academy of Regional Anaesthesia-AORA) is taken. An alcohol based $0.5 \%$ Chlorhexidine solution is used for skin preparation before the block procedure as per AORA recommendation.

All six nerves are blocked with the patient in the supine position. Hand and arm should be comfortably rested with the arm abducted, externally rotated \& forearm is supinated on a hand rest (Fig. 1).

An insulated needle $50 \mathrm{~mm}$ in length is chosen and the insertion points are subcutaneously infiltrated with $1 \mathrm{ml}$ of $1 \%$ lignocaine adrenaline using $2 \mathrm{ml}$ syringe.

Address of Correspondence: Dr. Surajit Giri, Pragati Hospital \& Research Centre, Sivasagar, Assam., E-mail: drsurajitgiri@gmail.com

DOI: 10.13107/ijra.2021.v02i01.029 | ( 2021 International Journal of Regional Anaesthesia | Available on www.ijrajournal.com | This is an Open Access article distributed under the terms of the Creative Commons Attribution Non-Commercial License (http://creativecommons.org/licenses/by-nc/3.0) which permits unrestricted non-commercial use, distribution, and reproduction in any medium, provided the original work is properly cited.

How to cite this article: Giri S | Landmark and PNS Guided Forearm Blocks | International Journal of Regional Anaesthesia | January-June 2021; 2(1): 67-71. 


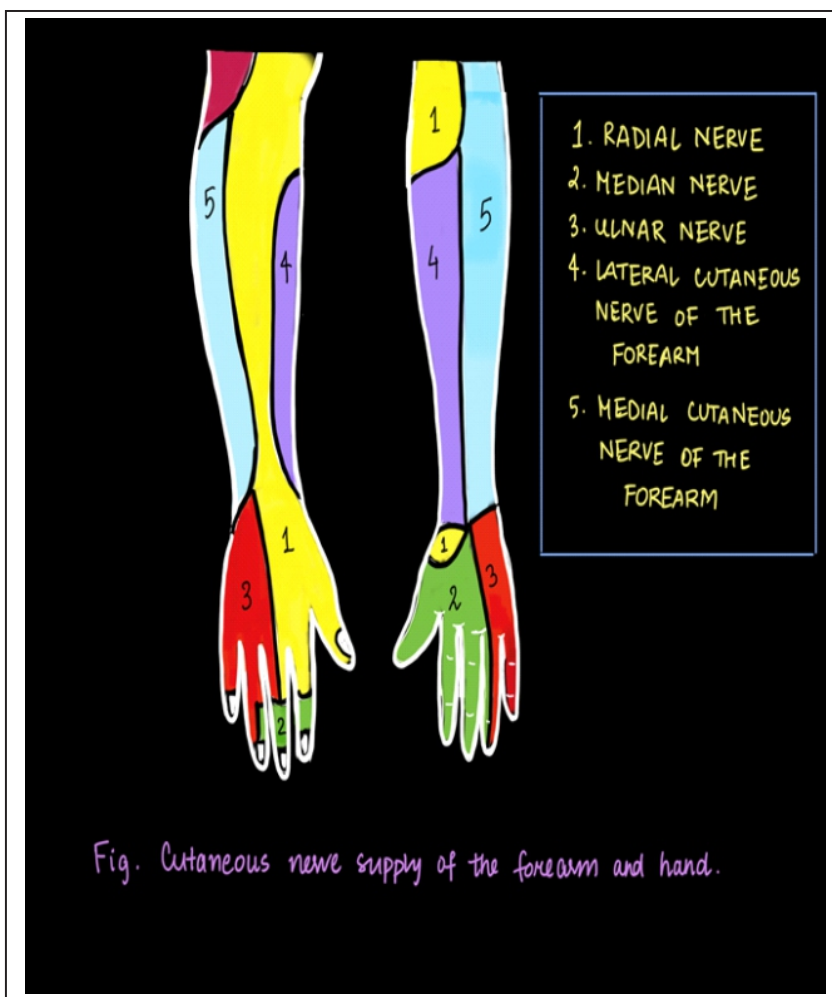

Figure A: Innervation of forearm and hand

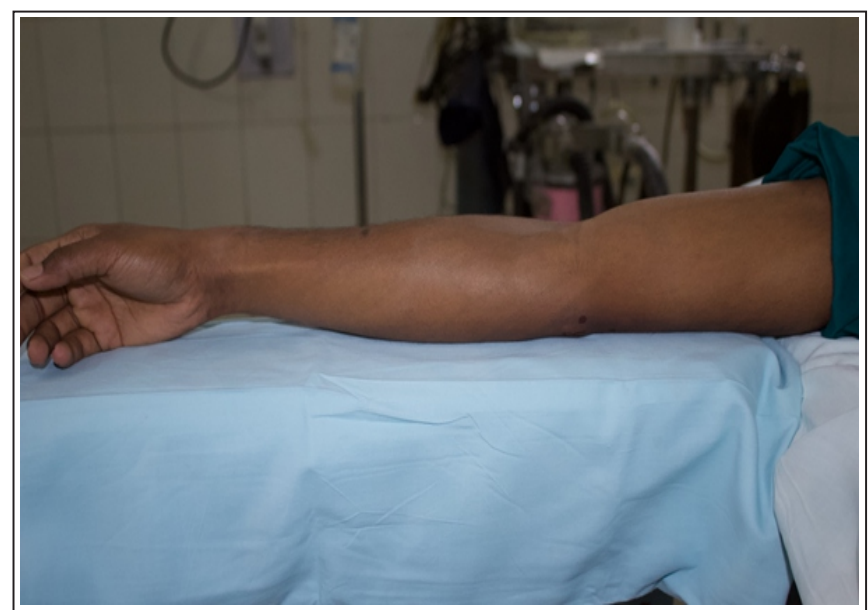

Figure 1: Comfortable (right) hand position. Patient is supine in the bed.

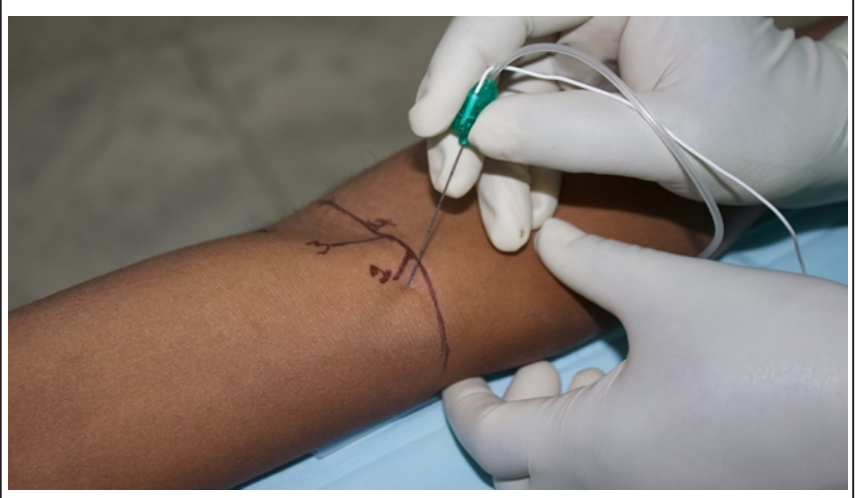

Figure 3: Left Elbow. Median nerve block. (1) Brachial artery. Needle is inserted $1 \mathrm{~cm}$ lateral to brachial artery pulsation.

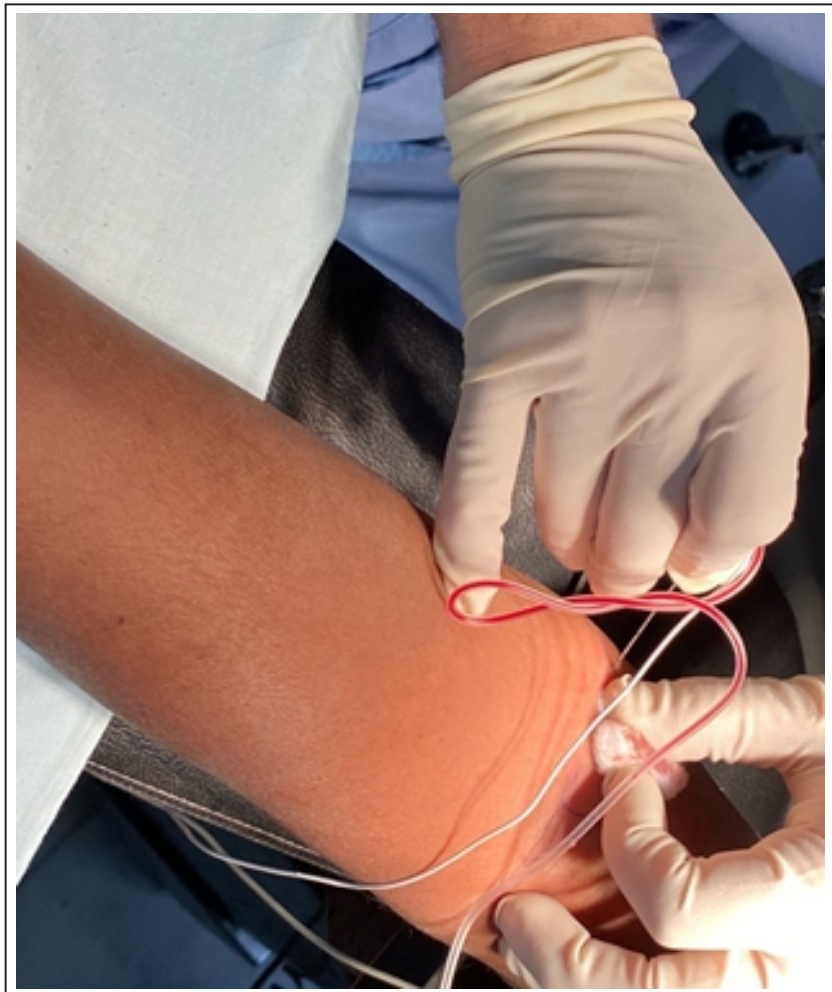

Figure B: Blood aspirated before injection of LA during Median nerve block in left Elbow.

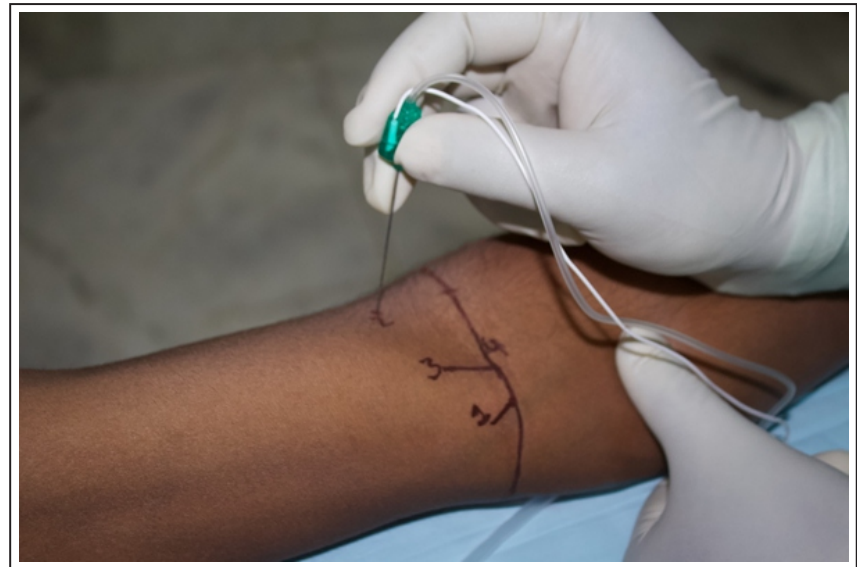

Figure 2: Left elbow. Radial nerve block. Needle is inserted $2.5 \mathrm{~cm}$ lateral and $2.5 \mathrm{~cm}$ cephalic to elbow crease, (3) Bicep tendon, (4) Elbow crease.

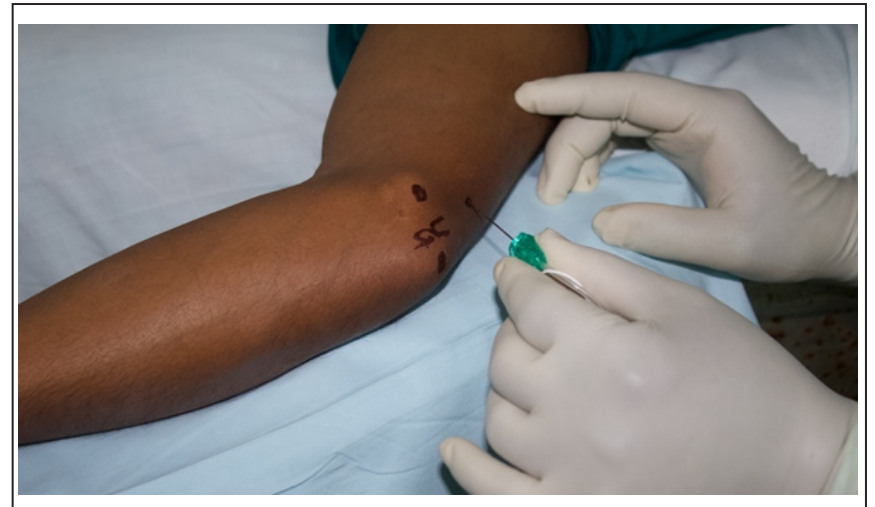

Figure 4: Right Elbow. Needle insertion point $2 \mathrm{~cm}$ proximal to ulnar groove (UG). 


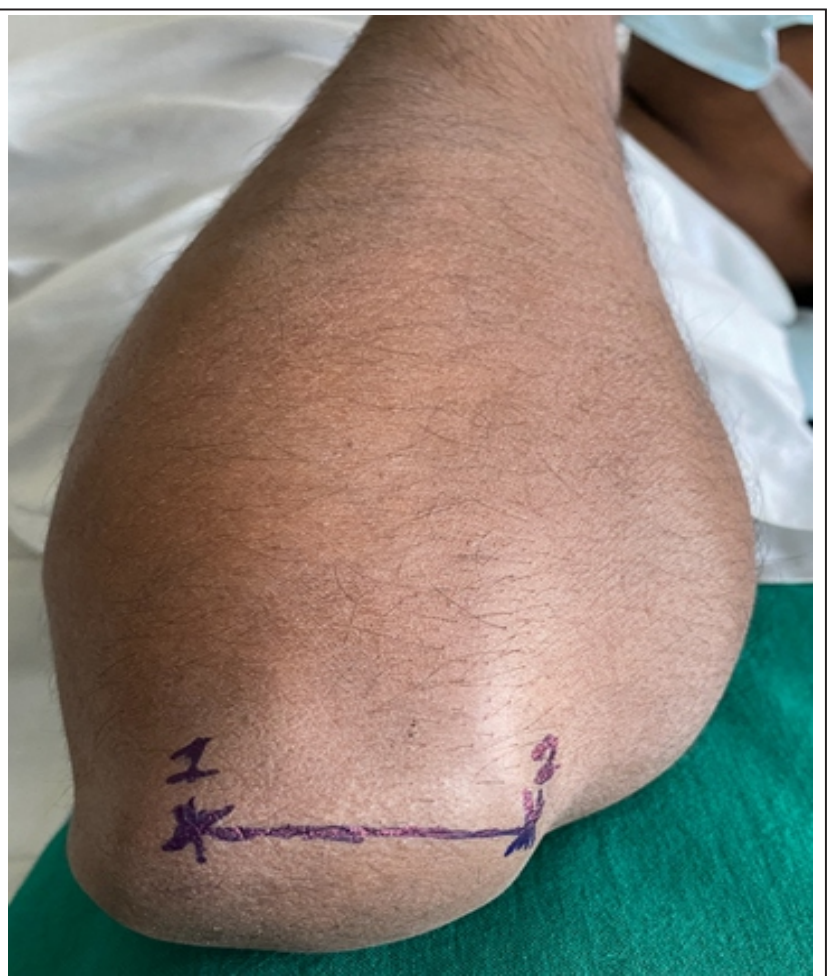

Figure 5: Left elbow. Posterior cutaneous nerve block. (1) Olecrenon process, (2) Lateral epicondyle of humerus.

The peripheral nerve stimulator (PNS) is set at $1 \mathrm{~mA}, 2 \mathrm{~Hz}$, $0.1 \mathrm{~ms}$. After getting the desired end motor response (EMR) at $1 \mathrm{~mA}$, the current amplitude is decreased slowly till 0.3 $\mathrm{mA}$. An EMR if elicited at less than $0.3 \mathrm{~mA}$ would suggest an intraneural needle tip position.

With appropriate positioning of the needle tip, $5 \mathrm{ml}$ of $0.5 \%$ Bupivacaine is injected after aspiration for blood. Fig. B demonstrates blood aspiration before LA injection in one of our patient. With initial $1 \mathrm{ml}$ of LA injection, muscle twitches vanishes (positive Raj Test), indicating needle is in the correct place. If after $1 \mathrm{ml}$ of LA injection, muscle twitches persists, it may indicate needle may be in the intraneuronal position. Reposition the needle is necessary in the above scenario. Injection of LA should be without resistance, and if patient complains pain and paraesthesia during injection, injection should abandoned.

\section{Sedation}

Children below the age of 10 years, requires sedation with inhalational anaesthetics, propofol $1 \mathrm{mg} / \mathrm{kg}$ and ketamine 1 $\mathrm{mg} / \mathrm{kg}$ body weight.

\section{The Elbow Crease}

With the arm in extension and supination, the elbow crease is on the line joining the medial and lateral epicondyles of humerus. In the elbow extended, the elbow crease is $1 \mathrm{~cm}$ proximal to the joint line. Injection points lie $1 \mathrm{~cm}$ and $2 \mathrm{~cm}$ above the elbow crease for median and ulnar respectively. For radial nerve the injection point will lie $2.5 \mathrm{~cm}$ above the elbow crease. All blocks are performed with the forearm supinated and extended.

\section{Landmarks}

\section{Radial nerve \& lateral cutaneous nerve of forearm}

The radial nerve divides into sensory and motor branch 2 $2.5 \mathrm{~cm}$ above the elbow crease. A point is marked $2.5 \mathrm{~cm}$ lateral and $2.5 \mathrm{~cm}$ cephalad to the biceps tendon (Fig. 2). The insulated needle is inserted perpendicular to skin and directed slightly towards lateral epicondyle of humerus. EMR's are in the form of extension of thumb and fingers. A wrist extension is ignored and a lateral or medial redirection should obtain the extension of thumb and fingers. At a current of not less than $0.3 \mathrm{~mA}$, inject $5 \mathrm{ml}$ of $0.5 \%$ bupivacaine after aspiration for blood. During withdrawal of needle, inject $5 \mathrm{ml}$ of $0.25 \%$ bupivacaine after aspiration for blood in lateral direction to block lateral cutaneous nerve of forearm.

\section{Median nerve \& medial cutaneous nerve of forearm}

A point is marked $1 \mathrm{~cm}$ medial to brachial artery pulsation. At this point the insulated needle is inserted perpendicular to skin (Fig. 3). EMR's are in the form of flexion of first three fingers. A wrist flexion is ignored. Redirection of needle in medial or lateral direction will elicits the flexion of the fingers. At a current of not less than $0.3 \mathrm{~mA}$, inject $5 \mathrm{ml}$ of $0.5 \%$ bupivacaine after aspiration for blood.

During withdrawal of needle, inject $5 \mathrm{ml}$ of $0.25 \%$ bupivacaine after aspiration for blood in medial direction to block medial cutaneous nerve of forearm.

\section{Ulnarnerve}

At the elbow, ulnar nerve runs between medial epicondyle of humerus and olecranon process of radius in the ulnar groove. Arm is abducted and externally rotated $\&$ forearm is flexed. Ulnar groove is marked and identified. Never ever inject in the ulnar groove. Injection in this place will invariably causes nerve injury. A point is marked $2 \mathrm{~cm}$ proximal to ulnar groove (Fig. 4). Insert the insulated needle in cephalic direction. EMR's are in the form of flexion of fourth \& little finger along with apposition of thumb towards the little finger. At a current of not less than $0.3 \mathrm{~mA}$, inject $5 \mathrm{ml}$ of $0.5 \%$ bupivacaine after aspiration for blood.

\section{Posterior cutaneous nerve of forearm}

Identify \& mark the olecranon process (OP) of ulna and lateral epicondyle (LE) of humerus. A line is drawn between OP \& LE. $5 \mathrm{ml} 0.25 \%$ bupivacaine is subcutaneously infiltrated in the line (Fig. 5). 


\section{Advantages of elbow block as anaesthetic technique}

1. The block site is away from the vital structures such as pleura, phrenic nerves etc.

2. The proximal muscle are unaffected. Complete blockade of the limb muscles reduces the satisfaction level of patients [5].

3. Distal blocks offers intraoperative stable cardiovascular system [6].

3. Low volumes are injected for adequate block. The incidence of LAST (Local anaesthetic Toxicity) is negligible.

4. Forearm blocks are ideal for day care forearm surgeries $[7$, $8]$.

\begin{tabular}{|c|c|c|c|c|}
\hline Nerve & Landmark & Injection site & EMR & Remarks \\
\hline Median & $\begin{array}{l}\text { Brachial artery } \\
\text { elbow crease }\end{array}$ & $\begin{array}{l}1 \mathrm{~cm} \text { medial to } \\
\text { brachial artery } \\
\text { pulsation }\end{array}$ & $\begin{array}{l}\text { Flexion of first } \\
\text { three fingers }\end{array}$ & $\begin{array}{l}\text { Wrist responses } \\
\text { ignored }\end{array}$ \\
\hline Radial & $\begin{array}{l}\text { Bicep tendon } \\
\text { elbow crease }\end{array}$ & $\begin{array}{l}2.5 \mathrm{~cm} \text { lateral to } \\
\text { bicep tendon and } \\
2.5 \mathrm{~cm} \text { cephalic } \\
\text { to elbow crease }\end{array}$ & $\begin{array}{l}\text { Extension of thumb } \\
\qquad \& \text { fingers }\end{array}$ & $\begin{array}{l}\text { Wrist responses } \\
\text { ignored }\end{array}$ \\
\hline Ulnar & Ulnar groove & $\begin{array}{c}2 \mathrm{~cm} \text { cephalic to } \\
\text { ulnar groove }\end{array}$ & $\begin{array}{c}\text { Flexion of fourth } \\
\text { \&little finger along } \\
\text { with apposition of } \\
\text { thumb towards the } \\
\text { little finger }\end{array}$ & $\begin{array}{c}\text { Only flexion of } \\
\text { the little finger } \\
\text { ignored }\end{array}$ \\
\hline $\begin{array}{l}\text { Lateral } \\
\text { cutaneous } \\
\text { nerve }\end{array}$ & $\begin{array}{l}\text { Bicep tendon } \\
\text { elbow crease }\end{array}$ & $\begin{array}{l}\text { After radial nerve } \\
\text { block during } \\
\text { withdrawal of } \\
\text { needle }\end{array}$ & Doesn't apply & $\begin{array}{l}\text { Subcutaneous LA } \\
\text { injection }\end{array}$ \\
\hline $\begin{array}{l}\text { Medial } \\
\text { Cutaneous } \\
\text { nerve }\end{array}$ & $\begin{array}{l}\text { Brachial artery } \\
\text { Elbow crease }\end{array}$ & $\begin{array}{c}\text { After median } \\
\text { nerve block } \\
\text { during withdrawal } \\
\text { of needle }\end{array}$ & Doesn't apply & $\begin{array}{l}\text { Subcutaneous LA } \\
\text { injection }\end{array}$ \\
\hline $\begin{array}{c}\text { Posterior } \\
\text { Cutaneous } \\
\text { nerve }\end{array}$ & $\begin{array}{l}\text { Olecranon } \\
\text { process of ulna } \\
\text { Lateral } \\
\text { epicondyle of } \\
\text { humerus }\end{array}$ & $\begin{array}{l}\text { Line joining the } \\
\text { olecranon } \\
\text { process \& lateral } \\
\text { epicondyle }\end{array}$ & Doesn't apply & $\begin{array}{c}\text { Subcutaneous LA } \\
\text { injection }\end{array}$ \\
\hline
\end{tabular}

\section{Disadvantages}

1. Tourniquet are not tolerated by the patients.

2. Forearm blocks requires multiple injection pricks.

3. May increase the discomfort to the patient.

\section{Conclusion}

PNS \& landmarks guided blocks around the elbow is relatively easy to perform. These blocks are very useful as a rescue block to convert incomplete proximal brachial plexus block to a complete block. Blocks around elbow can be used as primary anaesthetic technique for forearm and wrist surgeries. Cutaneous nerve blocks are always required along with motor nerves to complete anaesthesia \& analgesia for forearm and hand surgeries. 


\section{References}

1. Maga JM, Cooper L, Gebhard RE. Outpatient regional anaesthesia for upper extremity surgery update (2005 to present) distal to shoulder. Int Anaesthesia Clin 2012;50:47-55.

2. Fredrickson MJ, Ting FS, Chinchanwala S, Boland MR. Concomitant infraclavicular plus distal median, radial, and ulnar nerve blockade accelerates upper extremity anaesthesia and improves block consistency compared with infraclavicularblock alone. BrJAnaesth 2011;107:236-42.

3. Stranding S, editor. Upper arm. Gray's Anatomy: The Anatomical Basis of Clinical Practice. 41sted. London: Churchill Livingstone; 2016.p. 837-61.

4. Gisela Meier,Johannes Buettner.Atlas of Peripheral Regional Anaesthesia : Anatomy \& Technique.3rdedition.Thieme;2013.p.244-63.
5. Fredrickson MJ, Price DJ. Analgesic effectiveness of ropivacaine $0.2 \%$ vs $0.4 \%$ via an ultrasound-guided C5-6 root/superior trunk perineural ambulatory catheter. BrJ Anaesth 2009; 103:434-9.

6. RalfE Gebhard,Tameem A-Samsam et al.Distal nerve blocks at the wrist for outpatient carpal tunnel surgery offer intraoperative cardiovascular stability and reduce discharge time. Anest Analg $2002: 95(2): 351-55$

7. Nicolas Dufeu,Florence Marchand-Maillet et al.Efficacy and safety of ultrasound guided distal blocks for analgesia without motor blockade after ambulatory hand surgery.J Hand Surgery Am 2014:39(4):737-43

8. Michiel Siebelt,Klaas A Hartholt et al.Ultrasound guided nerve blocks as analgesia for nonoperative management of distal radius fractures-two consecutive randomized controlled trials.J Orthop Trauma 2019:33(4):e124e130

Conflict of Interest: Nil

Source of Support: None

Acknowledgment: Figure A; Ms. Shreya Nandini Giri,

Class IX, Delhi Public School, Nazira, Sivsagar, Assam, India. 